Physicians, internists and house officers.' The book is divided into three sections dealing with medical disorders, trauma and special problems.

The section on medical disorders is divided into 32 chapters, each dealing with common symptoms (palpitations, rash and dizziness). The chapter starts with a generaf? introduction to the topic followed by lists of common, less common and 'other' causes of $\overrightarrow{\mathbf{t}^{3}}$ the complaint. This is followed by sections on history, examination and emergency diagnostic tests. There is then a useful short section entitled 'clinical reminders' and, $\frac{\overline{7}}{\overline{7}}$ finally, there are one or two paragraphs summarizing the salient features of conditions mentioned in the initial listings. This format is comprehensive and well written. It was, however, disappointing to find only six pages devoted to resuscitation compared with ${ }^{\text {s }}$ the 50 pages on poisoning. Undoubtedly, this reflects North American practice and $\overrightarrow{0}$ experience. Although the authors suggest in their preface that the format will allow the $\vec{\omega}$ reader to gain rapid access to information, the layout of the book which is in close set⿱ print, without diagrams or flow charts, is more attractive to the armchair browser than 3 . to the SHO in a panic. The authors are keen to teach by reasoning rather than by rote Laudable though this may be, it does not, on occasion, allow rapid access to important information. For example, information about bicarbonate therapy during cardiac arrest can only be found by reading a paragraph headed 'Electrocardiogram.'

There is a good section on the general principles of extremity trauma, but the section $\vec{c}$ dealing with the specific treatment of injuries lacks crispness. It is disappointing to sees Dexamethasone vaguely recommended in the treatment of head injury and the recommendation that all patients with any loss of consciousness should be admitted foroo observation.

The section of 'Special Problems in Emergency Medicine and Trauma' covers suth items as child abuse, diving accidents, electrical injuries, radiation illness and sexư⿱ assault. The authors' cursive style is ideal for these topics and these chapters areo generally well written.

Overall this book is worth buying at $£ 24.00$. It is, however, not the book to buy on the day that you start in the A \& E department. It will be good general revision material for ${ }_{\overrightarrow{3}}$ final year medical students, but is sufficiently deep to be of value also to those pursuing a career in accident and emergency medicine and preparing for higher examinations.

D. W. YATES,

Accident and Emergency Department, Hope Hospital,

Salford,

England

\title{
A Simple Guide to Trauma
}

By R. L. HuCKSTEP

Edinburgh. 1986. 397 pp.

Only 4 years have passed since the third edition of Professor Huckstep's guide was published; in view of the frequency with which a well-thumbed copy is seen on a desk in a casualty department or in the pocket of a white coat, supplies were exhausted and a ${ }_{0}^{-}$ new edition was prepared. The most obvious difference is that the text is bolder and $\stackrel{\odot}{\circ}$ 
clearer type. Less obvious is the slightly smaller size but this has not reduced the number of pages nor the vast amount of information that the book contains. There have been a few additions and modifications, mainly to include the fixative and other impants that Huckstep has developed.

Simple as the guidance is said to be, the discerning reader will doubtless appreciate it more fully than those for whom the book was written just how sound and detailed the guide is. With fractures, the emphasis is on the simpler but more reliable methods, but the place of internal fixation is clearly indicated without the confident enthusiasm that is not unknown in this connexion. Clearly, many will disagree with points of detail but that is only to be expected of any properly dogmatic presentation of any subject.

There are a few points of detail on which constructive criticism may be offered, mainly because I have found them to be pitfalls for the newcomers to this kind of work.

Dislocation of the shoulder can damage much more than the circumflex or axillary nerve, but few know this or test for it. The same applies to the posterior interosseous nerve and the anterior type of Monteggia's fracture-dislocation.

Posterior dislocation of the shoulder is so easily overlooked that this perhaps deserves a special warning. The same applies to the more complex fracture-dislocations of the foot and to fractures of the odontoid process of the axis.

In matters of fact: the dislocated lunate bone looks pentagonal rather than triangular in the antero-posterior view; fractures of the base of the fifth metatarsal are transverse, which distinguishes them from the longitudinal epiphyseal line; a pulled elbow may require either pronation or supination; and I think that 'post-ganglionic' is more appropriate than 'post-axonal' in connexion with injuries of the brachial plexus. I was interested to see that Huckstep has reverted to dressing burnt fingers separately instead of allowing the relative freedom of use that a plastic bag makes possible. However, the reader will quickly find out which to use in his or her hospital.

One may wonder how many anaesthetists would agree to give a general anaesthetic to allow a fratured femur to be manipulated in the patient's bed. I have to confess that my own efforts to do this (anywhere) have been remarkably unsuccessful. One may also wonder how doctors in spinal injuries units would react to the recommendation that an unconscious and paralyzed person should be prone, without special instructions about safeguarding the spinal cord.

Having said that, I can add that it would not surprise me if the fifth edition of this excellent guide were to appear within 5 years.

\section{P. S. LONDON}

Birmingham Accident Hospital,

Birmingham,

England

\section{Renal and Urologic Emergencies}

By A. E. Wolfson \& A. Harwood

Churchill Livingstone, Edinburgh. 1986. 304 pp. $£ 28.00$.

This work is part of the series Clinics in Emergency Medicine published by Churchill 